\title{
The Acoustics of Crime
}

\section{New Ways of Ensuring Young People Are Not Seen and Not Heard}

\section{MELISSA BULL}

GRIFFITH UNIVERSITY

\section{-INTRODUCTION}

In the past the reinforcement of road safety rules through the introduction of harsher penalties has largely been justified in Australia in terms of preventing serious injury and preserving life. Such changes have occurred during the last forty years to the regulation of alcohol consumption, speeding, wearing seat belts and giving way at intersections. But over the last ten years a new road problem has emerged: a range of behaviours collectively referred to as 'hooning'. Hooning is more often measured as excessive noise and loss of amenity rather than serious injury or loss of life. The anti-hooning legislation enacted in response to this problem has provided for motor vehicles to be confiscated and forfeited-measures previously considered controversial even in cases of serious repeat vehicle-related offences that caused death.

These punitive responses seem out of step with neoliberal principles of government founded upon respect for private property and individual rights. 
Neoliberalism is usually defined as an ideological framework centred on the increasing use of markets to regulate the interactions of self-policing individuals typically construed as 'consumers'. ${ }^{1}$ Neoliberalism also refers to the range of governmental strategies, sometimes involving invasive legislative programs, aimed at creating what Sparke calls a 'normative model of personhood' by creating a society of self-policing individuals. ${ }^{2}$ The more invasive strategies of government have typically been aimed at 'marginal' groups whose identities are held to pose a threat to the security of the community of orderly consumers. ${ }^{3}$ Seen in this light, the suite of anti-hooning legislation in Australia is consistent with the neoliberal trend toward ever-greater control over identity formation and expression. Most importantly, this trend exemplifies a neoliberal sensibility aimed at quietening unregulated noise. This article explores the introduction of anti-hooning provisions across Australia. It begins by outlining the targeted types of behaviour, then reviews the recently introduced range of legislative measures designed to limit these types of behaviour in the various Australian states and territories. It discusses how prescribed behaviours have been defined as problematic according to their acoustic and aesthetic dimensions and concludes by considering how rather 'draconian' authoritarian responses have become viable solutions to something that is often described as annoying, nuisance or loutish behaviour.

\section{-HOONING}

The Macquarie Dictionary of New Words describes 'hoon' as an Australianism, with the earliest citation found in Xavier Herbert's Capricornia, published in 1938. According to Herbert a hoon was 'that sort of flash person who fangs their car around for amusement'. ${ }^{4}$ His definition is consistent with those expressed in more contemporary popular culture. An Australian 'hot-rod' internet site, for example, explains 'we have all been one or seen one':

The slightly rebellious, sun-glass clad, ever so cool dude, usually spotted behind the wheel of something special, his arm mysteriously jutting out the window, usually with a smile a mile wide-he has an abnormally heavy right foot and it is believed gasoline flows freely in his veins. ${ }^{5}$

Other media sources are less complimentary, portraying hoons as young males who drive high performance or 'souped-up' cars, rev big engines, play loud music and 
travel with groups of 'testosterone-addled chums'.6 An officer of the Queensland Polices Service (QPS) describes a 'hoon' as:

a person who performs hooning activities such as organised illegal street racing, in vehicles that are often defective and unroadworthy. 'Hooning' involves a number of illegal activities with vehicles, including travelling at high speeds, street racing, burnout offences and playing loud music from car stereos. Hoons tend to congregate in groups where they network and organise locations to commit the offences. ${ }^{7}$

Indeed the QPS provides a useful list of the types of offending behaviour commonly described as hooning. At the top of the list, a 'burnout' is described as wilfully driving a vehicle in a way that causes the tyres or a substance (like oil) poured onto the road surface, or both, to smoke when the drive wheels lose traction with the road surface. 'Lapping' involves driving at a very slow speed repeatedly around a number of predetermined streets. The predominant complaint is the volume at which vehicle sound systems are operated during lapping. 'Drifting' occurs when a vehicle approaches a corner or intersection at relatively low speed and is then rapidly accelerated through the corner causing the rear of the car to slide out and the tyres to slip on the roadway and screech. 'Street racing' involves two or more vehicles side by side or in very close proximity to each other, which then simultaneously and rapidly accelerate to a higher speed. It is a test of acceleration, and a conviction requires evidence of a starting and finishing point but not of any speed in excess of the speed limit being attained. Associated with this are 'road blockades' where vehicles, travelling on multi-lane roadways, slow down to speeds well below the prescribed speed limit to allow vehicles at the front of the blockade to commit street racing offences from a rolling start. In addition there are 'speed trials' or attempts to establish or break any vehicle speed record on a road and competitive trials of any description designed to test the skill of any vehicle or driver or the reliability or mechanical condition of any vehicle on any particular road. Finally, 'parking up' occurs when 'hoons' gather in large numbers, 'look at each other's cars, network and arrange illegal behaviours'. Lisa Folkman of the QPS State Traffic Support Branch classifies some of these behaviours as 'irresponsible', some 'potentially dangerous' and others 'just annoying or threatening'.8 This article 
considers the recent responses to these types of behaviour and identifies noise as an important dimension to governmental responses.

\section{-A NEW LAW AND ORDER AUCTION}

As government interest in 'hooning' behaviour has grown, use of the term has become semi-official in Australia with police and governments increasingly referring to legislation targeting anti-social driving activities as 'anti-hoon laws'. The term now appears in the titles of legislation in a number of states and territories. Examples include Victoria's Transport Legislation Amendment (Hoon Boating and Other Amendments) Act 2009, the Road Transport Legislation Amendment (Car Hoon) Act 2008 in New South Wales and the Northern Territory's Transport Legislation (Hoon Behaviour) Amendment Act 2009. Since legislation to regulate this type of behaviour was introduced in 1996, there has been an escalating law and order auction with all Australian states and territories introducing increasingly harsh penalties for these types of offending behaviour as they seemingly work to outdo each others' provisions.

The NSW Traffic Amendment (Street and Illegal Drag Racing) Act 1996 was the first off the block. It was drafted to provide the New South Wales police service with the power to confiscate the vehicles of anyone engaged in such illegal activity. The amendment was intended to address the apparent failure of existing laws and punishments to effectively dissuade offenders from repeatedly participating in 'illegal racing on public streets, burnouts, doughnuts and other dangerous practices'. ${ }^{9}$ Then NSW Minister for Police, Paul Whelan, described it as 'innovative legislation', as it provided 'new powers which allowed the police to impound any motor vehicle used for unlawful street racing, either on the spot or if circumstances require at a later date'.10 Building on this foundation, the NSW Road Transport (General) Act 1999 provided the authorities with powers to remove and impound motor vehicles used in such offences; impound or forfeit on finding of guilt or admission; search motor vehicles used in unauthorised racing, speed trials burnouts or any like offences; and suspend the offending driver's licence (whether or not the licence was issued in New South Wales). In the Australian Capital Territory the Road Transport (Safety and Traffic Management) Act (1999), introduced later the same year, mirrored the NSW amendments. 
In Queensland, the Police Powers and Responsibilities and Another Act Amendment Bill 2002 outlined provisions similar to those described above. While the NSW legislation specifically provided for the suspension of driving licences, the proposed Queensland legislation did not. Queensland's Police Powers and Responsibilities Act 2000 was amended to give police the power to impound the vehicles of drivers committing prescribed hooning offences including dangerous operation of a motor vehicle, careless driving of a motor vehicle, racing and speed trials on roads, and wilfully starting a vehicle, or driving a vehicle, in a way that makes unnecessary noise or smoke. Among other sanctions imposed (including fines, demerit point deductions, and licence disqualification) the vehicles of drivers so charged could be impounded for forty-eight hours for a first offence, three months after a second offence within three years, and forfeited to the state after a third offence within three years.

In 2004 the Tasmanian Police Offences Amendment Bill and the Western Australian Road Traffic Amendment (Impounding and Confiscation of Vehicles) Act 2004 set out stipulations similar to those of the Queensland legislation (forbidding activities such as racing, causing a deliberate loss of traction, or creating unreasonable noise or smoke due to driving). The South Australian Statute Amendment (Misuse of Motor Vehicle Act) 2004, or the 'hoon drivers' legislation created two new summary offences relating to the driving of a vehicle in a public place that involves any 'competitive trial to test drivers' skill' or the sustained wheel spin (section 66(2)(a-d)). Penalties including impounding and forfeiture were later described in the Criminal Law (Clamping, Impounding and Forfeiture of Vehicles) Act 2007. The Northern Territory introduced similar 'anti-hoon' legislation providing sanctions for anti-social driving practices, such as burnouts and road races. ${ }^{11}$ In 2006 amendments to the Road Safety Act 1986 brought Victoria into line with these other states and territories.

Toward the end of the first decade of the twenty-first century, states and territories repeatedly tried to outbid each other in their efforts to introduce the toughest penalties for 'hooning'. The New South Wales Parliament in 2008 toughened penalties through the Road Transport Legislation Amendment (Car Hoons) Bill. The penalty for street racing was increased to $\$ 3,300$ for a first offence and to $\$ 3,300$ or nine months imprisonment, or both, for a second or subsequent offence. 
The aim was to more effectively deter 'hoons' who persisted in committing street racing offences by threatening a jail term for a second offence. The criteria defining a burnout were expanded and the penalties doubled (to ten penalty units or $\$ 1,100$ ). Previously, aggravated burnouts were defined as burnouts committed with the knowledge that an inflammable liquid was on the road. The 2008 legislation expanded the definition to include repeated burnouts, long and loud burnouts that disturb community amenity, burnouts that endanger public safety and burnouts that are committed as part of a group activity. The penalty for aggravated burnout was increased to $\$ 3,300$ for a first offence and $\$ 3,300$ and up to nine months imprisonment or both for a second or subsequent offence. Aggravated burnouts were described in the parliament as the 'worst types of hoon behaviour'. The objective was to address those people who 'deliberately do long, noisy burnouts' down public streets or as part of an illegal street race. ${ }^{12}$

The 2008 bill introduced offences that extend to groups of friends and associates that may gather to watch, or urge others on, or who photograph or film the activities to glamorise them. The penalties for spectators are the same as for drivers: $\$ 3,300$ for a first offence and $\$ 3,300$ or nine months imprisonment or both for a second or subsequent offence. A July 2012 internet search with the words 'youtube, burnout, New South Wales' - that is, to find visual recordings of public displays of such behaviour-returned a result of about 280,000 even though both recording and burnouts are now illegal in New South Wales. This figure raises doubts about the effectiveness of the provisions.

In 2011, Queensland, Victoria and the Northern Territory all increased the length of time for which vehicles could be impounded. In Queensland cars are now impounded for seven days on a first hooning offence and twenty-eight days on the second, with police able to apply for impoundment for up to three months. Subsequent offences provide authorities with the right of permanent forfeiture. Each offence carries fines between $\$ 200$ and $\$ 900$, and impound charges of $\$ 25$ per day (\$700 per month).13 In Victoria the vehicles driven in repeat offending are seized for a minimum of forty-five days. This can be extended to a maximum of three months, or the vehicle can be seized permanently. The number of offences considered 'hooning' has been increased to include repeat drink, drug and unlicensed driving, along with overloading a vehicle with passengers. ${ }^{14}$ In the Northern Territory 
toughened laws allow vehicles to be immediately impounded for forty-eight hours on a first offence and the offender fined $\$ 220$. On a second offence the court can impound a car for between three and six months with a fine of up to $\$ 2200$ or twelve months imprisonment. On a third offence the car can be forfeited and disposed of by the court with a fine of up to $\$ 2200$ or twelve months imprisonment. Offenders are billed for the cost to remove, transport and store impounded vehicles. ${ }^{15}$

\section{—RATIONALES FOR RESPONDING TO HOONING BEHAVIOUR}

In 1996, during debate on the draft of the NSW act, parliament acknowledged that confiscating cars appeared somewhat anomalous as a punishment when compared to the fines and other punitive measures provided for other road traffic offences. The South Australian Statute Amendment (Misuse of Motor Vehicle Act) 2004 had some safeguards against abuse, but impounding and possibly forfeiting a vehicle was seen by critics as a dramatic response to the misuse of a motor vehicle. ${ }^{16}$ In 2010 when a Perth doctor's Lamborghini was impounded even though he wasn't driving it at the time, the Western Australian Police Minister Rob Johnston admitted that the laws were 'unfair' but he also stood by them. ${ }^{17}$

A key concern about anti-hooning provisions has been their tendency to be out of kilter with other law enforcement sanctions. In 2002 a Queensland parliamentary research brief on the legislative context cites a spokesperson for the Royal Automobile Club of Queensland (RACQ) who acknowledged some areas of the state were experiencing 'problems with outlandish driver behaviour' but expressed the view that the proposed anti-hooning legislation might contain penalties greater than the offences warranted. This criticism was echoed by the Council of Civil Liberties, whose representative argued that the existing legislation (prior to the amendments) was sufficiently strong enough to deal with such behaviour. A spokesperson for the peak representative body Youth Affairs Network of Queensland criticised the proposed legislation on the grounds that it would unfairly discriminate against young people.18 These submissions were consistent with the view of Dr Michael Henderson, a consultant road safety researcher, expressed in the 1997 New South Wales Staysafe inquiry which evaluated the effectiveness of the 1996 Traffic Amendment (Street and Illegal Drag Racing) Act. Henderson said: 
As a road safety person I cannot accept the validity of using this type of draconian penalty for an offence which overtly does not have a very dangerous effect. Clearly there is a hazard, but so has jet skiing and hang gliding and a whole host of other things. But clearly it has a high nuisance effect.

If we want to put aside the option of using these kinds of draconian penalties for persons who are a serious threat to mankind, such as drink drivers, I think we lose something by using this type of penalty for essentially what is a nuisance activity. ${ }^{19}$

According to Glen Fuller, a Sydney-based social researcher interested in car-related behaviour, the practice of street racing and to a lesser extent cruising can appear dangerous and even sinister but the statistical evidence, as Henderson suggests above, indicates otherwise. ${ }^{20}$ Fuller argues that the percentage of so-called hooning accidents in Queensland is insignificant in the context of all road accidents. Kerry Armstrong and Dale Steinhart's study discovered that for the targeted age group of twelve to twenty-four years there were 169 hooning related accidents involving injury and property damage in the period 1999 to 2004.21 The publicly provided road safety statistics from the Queensland Road Safety Authority indicated that there were over one hundred thousand accidents in Queensland in the period 1999 to 2003 (five years compared to six).22 Fuller calculated that hooning accidents represented roughly less than one quarter of one per cent of the total number of recorded accidents. He points out that this not how things are portrayed in the media or in political rhetoric. On his account, as a road safety problem hooning is simply not that dangerous. ${ }^{23}$ Indeed if we consider how the problem has been framed and the rationalisations for the responses, the risk to life and limb posed by hooning behaviour does not seem to be the primary consideration-which it is with other driving offences, such as speeding or driving under the influence of alcohol, that attract similarly heavy penalties. The dangers posed by hooning do not explain why the behaviour has been the subject of such intense and heavy-handed legislative responses. An important element that does move towards an explanation is how such legislation imposes neoliberal normalising standards of conduct in which sensibilities around the production of unregulated noise in urban spaces plays a key role. 
The Queensland Parliamentary Library Research Brief No. 2002/18, Police Powers and Responsibilities and Another Act Amendment Bill 2002: Confronting bad and nuisance road behaviour, explored the potential for the introduction of anti-hoon legislation in that state. ${ }^{24}$ The preface to the paper (appearing as a lone statement on the title page) explains that the Act is 'primarily aimed at clamping down on loutish behaviour involving motor vehicles on public roads. Behaviour such as burnouts, street racing and using loud sound systems is specifically targeted.' The introductory section begins: 'The intention is to grant greater powers to police to deal with deliberate driving behaviour that is annoying and perhaps dangerous to other road users and/or nearby residents.' ${ }^{25}$ It is difficult not to conclude from these opening remarks is that the problem to be addressed is judged in value terms to be 'bad', 'nuisance', 'loutish', 'annoying' and only 'perhaps dangerous'. Indeed the body of the paper goes on to describe hooning as 'the flamboyant manoeuvres of some car enthusiasts', a perception reinforced by the comments of a local government councillor who explained: 'If these kids were just getting together to look at the cars, there would not be an issue. The problem is the danger involved in doing spin-outs, doughnuts and the rest of the sideshow.'26

A suburban resident provided more details of the danger, describing gatherings that in January 2002 had been occurring on a weekly basis for about six months:

They park on both sides of the street and in every available parking space. They slowly rev up and down the street for hours. Not only is it highly dangerous, but it is very intimidating, they are all leaning against the cars, alarms are going off, car horns are going, and engines are revving.

They appear to have a system in place that warns of any imminent arrival of police.

It would be wonderful if they took it in turns to meet outside their own homes and completely disrupt the neighbourhood with noise. ${ }^{27}$

Indeed, police data from South Australia indicates that, when it comes to hooning, noise is a key concern. Between 2005 and 2007, 80 per cent of 1100 recorded hooning offences involved sustained wheel spins (burnouts) or engine or tyre noise, almost 10 per cent involved driving on a park or garden, and only the remaining 10 per cent were citations for racing or speed trials. ${ }^{28}$ 
In the debate around the legislation, the provisions of the legislation to regulate sound rather than speed; road safety statistics and the views of experts suggest the offences associated with hooning 'do not have a very dangerous effect', and noise and amenity, rather than loss of life or limb, seem to be a key concern of the legislation. To understand this auditory dimension to regulating driving behaviour, we need to consider what Brandon Labelle describes as the 'acoustic politics of space'. Doing so acknowledges that the auditory experience of hooning is 'locational and poignantly embedded within processes of social exchange'. Sound weaves individuals into a larger social fabric but, as the example of hooning demonstrates, this can be a discordant rather than harmonising process. As Labelle points out policies in urban noise abatement, which hooning legislation now contributes to, 'interestingly reveal the degree to which acoustic space and its ubiquitous impingement is ... difficult to control'. Because it allows flexible participation acoustic space is often disruptive. As we have seen, vehicle related noise 'sparks annoyance and outrage'. ${ }^{29}$

According to Labelle, in urban settings silencing domesticates the social; it relegates and constrains through a notion of social respect and consideration of the forces always already within the social.30 Noise is an index of movements and bodies, a register of unlicensed behaviour, but silencing is an index of the limits of particular social climates. An auditory geography exists at the intersection of noise and silence, forming a continual articulation of what is permissible. Exposure to noise and silence are linked to place and placelessness. From Labelle's perspective noise is that sound that occurs where it should not. It disrupts the particular setting. Commands of silence and silencing are place-based concepts applied to situational events and architectural spaces. Though certain sounds-like the screech of wheels on bitumen, the throaty rev of a powerful engine, the snarl of a loud exhaust systems or the continuous 'doof' of a bass line-may disturb wherever they occur, these sounds gain in specificity and intensity when located and brought into relational play in the suburbs. This is reflected in the histories of noise abatement policy.

Research in the United Kingdom has identified domestic noise and 'noisy neighbours' as one of the top two areas of complaint by the population. ${ }^{31}$ In that country, and in other liberal democratic states, the act of disturbing the neighbours has stimulated the development of elaborate networks of legislative and social 
challenges. Urban design has struggled to respond to the problem of neighbourhood noise. A key facet of suburban planning is the constitution of community life that is still conventionally understood in terms of striking a balance between a vibrant public sphere and a private realm of personal independence and freedom. As even those sceptical of the dominance of neoliberalism in urban design admit, however, contemporary city planning calls into question any clear public/private definition, as the encroaching 'privatisation' of public space attests. ${ }^{32}$ Recent trends in urban planning exemplify patterns of sequestration and quietening of community in suburban 'enclaves' of protected relative affluence, of order and security, peace and quiet. ${ }^{33}$ Strategies for securing and controlling access to neighbourhoods rely on street layouts. For example, developers over time replaced the grid layout of streets with interrupted parallels and ultimately loops and lollipops in which the main boulevards are complemented by sets of residential streets ending in cul-de-sacs. The lollipop layout, by limiting the movements of random passersby, discourages free access. "These street patterns thwarted easy automobile access and created successively more self-contained, self-focused and unconnected subdivisions that made it easier for residents to control their own space'. ${ }^{34}$

Through design, suburban neighbourhoods coalesce around a set of common attributes: 'lifestyle' is defined and constituted through planning practices to eliminate the chance of confrontation or disruption. Commonality found in the suburb operates as a means of creating a 'neighbourhood', a controlled and safe environment. In the suburbs, silence acts as a principle of social order. As an imagined base for harmonious living, a quieter environment necessarily shapes the possibilities for social interaction, characterising 'the other' or 'the outsider'signalled by sound out of place-as noise interrupting commonality. 35

To illustrate this argument Labelle describes amendments to city ordinances in Valencia, USA, that allows police enforcement officers responding to 'loud party calls' to cite the homeowner rather than the offending person. These provisions are aimed at loud parties thrown by teenagers specifically when parents are away. Previously, the teenager would be fined for the disturbance without parents necessarily having to know. With the amendment the fine was directed to the actual homeowner and alerted parents to their children's activities. The loud party is a primary example of a suburban confrontation between neighbours that leads to 
complaints, police involvement and penalty. Through planning regulations the suburb caters to a particular and quietly ordered vision of adult community life. In this setting specifically teenage life-such as loud parties or outlandish driver behaviour-challenges the established and controlled codes of commonality by breaking the rules. ${ }^{36}$

Elements of the anti-hooning legislation described above parallel these loud party amendments. The provision that vehicles could be impounded regardless of whether or not the driver is the registered owner was not part of early forms of legislation first introduced in New South Wales and Queensland. It became a feature of provisions in jurisdictions that subsequently adopted this style of legislation. From the outset in Tasmania the police information about anti-hoon legislation warned: 'It doesn't matter if the car you are driving at the time of the offence is yours or not'. ${ }^{37}$ In 2008 Paul Holloway, the South Australian Minister for Police, boasted that amendments which strengthened legislation in that state offered 'some of the harshest penalties in the country'; he warned that the family car was not exempt from being impounded, and that police had the power to impound a vehicle involved in hoon activity regardless of whether or not the driver is the registered owner. ${ }^{38}$ In Victoria, according to then Minister for Police and Emergency Services Tim Holding, 'three strikes and the vehicle's out: sold by the state of Victoria, which will keep the proceeds'. The family car was not exempt from impoundment, or permanent confiscation, so parents needed to ensure their children did not engage in hoon driving behaviour. 'Authorities have the power to impound, immobilise, or confiscate, any vehicle involved in a hoon act, regardless of whether or not the driver is the registered owner' ${ }^{39}$

In New South Wales when offenders use their own vehicle it can now be impounded, clamped or forfeited to the Crown. A vehicle that is forfeited may be sold or provided to the Road Transport Authority (RTA) to be used for crash testing or education programs. Restrictions have been placed on the court's discretion to reduce, commute or dispense with a period of confiscation or forfeiture. Penalties cannot be reduced because of inconvenience. Difficulty carrying out employment or in travelling to or from a place of employment, business or education is not considered sufficient to constitute extreme hardship. Where a driver is found guilty in someone else's vehicle, sanctions can now be placed on the registered operator of 
that vehicle. The hardship clause is similarly applied: 'Vehicles will not be returned because of weak excuses, or because they suddenly have to find alternative means of carrying out their day to day life.' 40 The RTA can issue the registered operator with a suspension warning notice that additional sanctions will apply if any vehicle owned by them is used in the commission of a further street racing or aggravated burnout offence within five years of receiving the warning. Vehicles' registration can be suspended for up to three months. Providing for the clamping, confiscation or forfeiture (and other penalties) of vehicles that are not the property of the offender not only silences the vehicle through immobilisation, it also ensures that others take responsibility for how motor vehicles are used. Particular attention is paid to parents regulating the behaviour of their children, and vehicle owners more generally being attentive to how their property is used. The theme of others having responsibility for limiting hooning behaviour also underlies the extension of penalties in the 2008 New South Wales legislation, described above, to those who may gather to watch, urge others on or photograph or film to glamorise the activity.

\section{-ACOUSTIC IDENTITIES}

Cars have long been recognised as vehicles for the expression of identity, with particular styles of design and modification being associated with particular groups, often those who are marginalised or experience tension within mainstream culture. The car is a sound-emitting machine: it creates noise and vibration through its impact and contact with road surfaces, at the same time providing the possibility for an individualised soundtrack to the driving experience through its own entertainment system. The car is a canvas allowing symbolic expression not only through paint jobs and body shaping but also as an audible machine: a vehicle for the expression of identity through amplification. ${ }^{41}$

George Prochnick explains how the expressiveness of car culture spans the globe. It has taken the form of car-body modifications: paint jobs, pin striping, chroming, large fins, hydraulic systems that lift and lower the vehicle, aestheticisation of engines, suspension systems and all such related parts (gold or chrome plating for instance). In addition to visual customisations engines and exhaust systems are modified to produce a particular sound, or extreme sound systems are installed to provide sonic customisation. Manufacturers appeal to 
particular consumers by sonic branding or soundscaping within vehicles. ${ }^{42}$ When Harley Davidson was forced to comply with noise regulations that outlawed the motorcycle's ear-splitting roar, the company responded to the demands for motorcycles with the distinctive and unmistakable Harley Davidson sound by engineering a product that would still sound just like a Harley only quieter-they dampened the whines and knocks and other undesirable mechanical noises while adjusting the exhaust and engine design to maintain the desired balance of tone, pitch and beat. Similarly, customer surveys indicated that the noise of Jaguar engines was being poorly received. Through focus groups, Jaguar discovered that while the benchmark for sound had been set in accordance with that of a luxury car rival known for the sophisticated quiet of its engine, Jaguar drivers wanted two different acoustic experiences at the same time: one of refinement, the other of power. Jaguar soundscaped its engine to create the right balance between the purr and the roar. ${ }^{43}$ In contrast, to create a sonic experience that was appealing to certain types of driver Honda paid a large sum of money to soundscape a busy road. The project involved cutting thousands of tiny grooves into the asphalt so that the road surface would 'play' the William Tell overture as cars drove across it. It played best for Honda Civics travelling at fifty-five miles an hour. People living nearby were forced to endure the endlessly repeated snatch of Rossini and, as the road surface corroded with use, the music was similarly degraded. ${ }^{44}$ As with visual modifications, the customisation of the acoustics of cars is intimately linked to identity: it can expression particular types of subjectivies and constitute particular identities requiring more or less regulation.

The car has long been associated with youth culture and resistance to authority. Since the 1950s it has been a means of escaping parental supervision. O'Dell describes how, for young people, the mobility of the car provides a vehicle for escape from claustrophobic living conditions and parental control. It offers a free space to express identities. O'Dell goes on to explain how, for some young people, the car constitutes an arena around which it is possible to test and slightly stretch the limits of 'acceptable behaviour' as they drink, sing, scream, play loud music and shout greetings to unknown pedestrians. 45

The car accommodates both deviant and non-deviant behaviour. It is a mobile gathering space that can be interpreted through differing cultural perspectives. 
Familiar forms of cultural expression associated with cars include gang culture, car clubs and car competitions. A recent acoustic variation has been the development in the United States of the culture of $\mathrm{dB}$ (decibel) drag racing which turns the automobile into an object not only for new forms of display and relation, but also a device for sport. $\mathrm{dB}$ racing-also known as bass racing or sound pressure level (SPL) competitions-is a competitive sport that uses the automobile as an acoustic shell to drive or 'race' bass frequencies. Competitors customise their cars for optimum sound pressure levels, often eliminating superfluous elements from the car. ${ }^{46}$

Based on Australian research Leal et al. suggest hooning could be viewed as part of young driver culture. ${ }^{47}$ Those associated with hooning have been identified as being mainly young men, with most between the ages of sixteen and twenty-five years. ${ }^{48}$ In mid 2011 The Motor Report, citing Victoria Police statistics collected since the introduction of anti-hooning legislation, explained that about 96 per cent of hoon offenders are male, and almost 80 percent are between the ages of eighteen and twenty-nine. ${ }^{49}$ Gerry McCarthy, then Minister for Transport and Minister for Corrective Services in the Northern Territory, in the second reading speech for the Transport Legislation (hoon behaviour) Amendment Bill 2009 identified the demographics most likely to be involved in hoon driving behaviour as 'young males between seventeen and twenty-six years of age', and concluded that the legislation 'targets young people'. ${ }^{50}$ In short, the problem behaviour has been constituted as something characteristic of (a few) mainly young men who eventually grow out of it. 51

Hooning behaviours, like street racing, have been described as transitory activities, with most people racing for only two or three years. ${ }^{22}$ This assessment is consistent with results from Armstrong and Steinhardt's interviews with car enthusiasts, which differentiated between 'enthusiasts' and those who are involved in the antisocial element of car culture or 'hoons'.53 The car enthusiasts interviewed identified the problematic element of the scene as a small group-approximately 10 per cent of the entire population-that would be present at a venue or an event on a particular night. The interviewees distanced themselves from this subgroup preferring to identify themselves as car enthusiasts. Beyond this dissociation there was, however, ready acknowledgement that 'because someone may currently not be a socially responsible member of the scene that this will not always be the case'. ${ }^{4}$ 
Participants noted how younger members of the scene, including themselves some years ago, were more prone to take part in inappropriate or illegal behaviours. From this perspective many of the legislatively prohibited behaviours associated with hooning-burn outs, lapping, drifting and parking up-contribute to the acoustic expression of youth car culture.

\section{-CONCLUSION}

The term 'danger' is often used in relation to hooning. As quoted earlier, Lisa Folkman of the QPS described some hooning behaviours as irresponsible, some potentially dangerous and some just annoying or threatening. Glen Fuller described how car-related behaviour can appear dangerous (and even sinister). And according to the suburban resident cited above, danger in the context of hooning is not so much related to speed as to threatening and intimidating behaviour: cars slowly revving up and down the street for hours, alarms going off and car horns blasting. Moreover, this behaviour is presumed to be out of place: these young people are not meeting outside their own homes or disrupting their own neighbourhoods with noise.

Fredrico Miyara would define the noise associated with hooning as acoustic violence: 'Acoustic violence is just violence exercised by means of sound. Often such sound will be loud noise, but it might also be the neighbour's [or young driver's] music ... or the constant hum of a busy city late at night when one is trying to sleep.'55 LaBelle rightly suggests that by drawing parallels between sound and violence Miyara positions acoustic violence within a hard moral frame. This is important because violence and suffering demand a clear response, like harsh legislation and heavy penalties. ${ }^{56}$ This formulation, however, fails to consider how silence might also act violently. Silencing has a long association with punishment and discipline. ${ }^{57}$ Through its harsh provisions hooning legislation is a reductive response that aims to silence particular forms of expression and regulate the development of particular youthful identities. The analysis above demonstrates how contentious debates surrounding noise, in this case produced through hooning behaviours, seek to achieve a quieter environment and in doing so mirror particular moral regimes that locate deviant behaviour as inherently out of place. Designing quieter neighbourhoods as a civic project tends to position noise on the side of 
violation, and links social difference to forms of audible excess and annoyance. Planning and legislation that defines limits and minimises volume, vibration and leakage seeks to order neighbourhoods in ways that insulate the community from the 'other' - the teenager or young driver, for example-thereby linking notions of quiet to the maintenance of domestic stability. In the quest to secure more humane audible environments, the pursuit of silence paradoxically supplies the mechanics of social values with a vocabulary of control and constraint.

Melissa Bull is a criminologist at Griffith University. Her work focuses on tensions in contemporary programs of policing between governance through exercising legitimate authority and the managing liberal freedoms. It involves theoretically informed policy analysis that explores endemic public policy difficulties while seeking conceptual and practical solutions.

\section{-NOTES}

1 John Clarke, 'Dissolving the Public Realm? The Logics and Limits of Neo-liberalism', Journal of Social Policy, vol. 33, no. 1, 2004, pp. 31-8.

2 Matthew B. Sparke, 'A Neoliberal Nexus: Economy, Security and the Biopolitics of Citizenship on the Border', Political Geography, vol. 25, 2006, pp. 154-5.

3 Katharina Eisch-Angus, “'You can't argue with security”: The Communication and Practice of Everyday Safeguarding in the Society of Security', Behemoth: A Journal on Civilisation, vol. 4, no. 2, 2011, pp. 88-9. ${ }^{4}$ Glen Fuller, 'The Hoon: Controlling the Streets?' in Outrageous!: Moral Panics in Australia, ed. Scott Poynting and George Morgan, ACYS, Hobart, 2007, p. 124.

5 Victorian company 'Hoon Auto Gear - Australia', <www.hot-rod.com.au/links/members/htm> (accessed 24 February 2012).

6 For example, Altman 2006, Johnson 2007, Penberthy 2004, Russell and Cooke 2006 cited in Nerida L. Leal, Barry C. Watson and Mark King, 'Hooning Offenders and Offences: Who and What are we Dealing With?' Australasian Road Safety Research, Policing and Education conference, Melbourne, 17-19 October 2007, p. 5.

${ }^{7}$ Lisa-Marie Folkman, 'Queensland's Anti-hoon Legislation and Policing Methods used to Prevent Hooning Behaviour', Road Safety, Research, Policing and Education Conference Proceedings, Wellington, New Zealand, 14-16 November 2005, p. 2. 
8 Folkman, p. 3.

${ }_{9}^{9}$ Staysafe 35, The Traffic Amendment (Street and Illegal Drag racing) Act 1996-Report Relating to the Sunset Provision, New South Wales Parliament, Sydney, 1997, p. 8.

10 Staysafe 35, p. 8.

11 Territory Roads, Annual Report 2003-2004, Department of Infrastructure, Planning and Environment, Darwin, 2004, pp. 73-7.

12 Penny Sharpe, 'Legislative Council Second Reading Speech, Road Transport Legislation Amendment (Car Hoons) Bill 2008 NSW—5/03/2008', New South Wales Parliament, Sydney, 2008.

13 Police Powers and Responsibilities Act 2000 Queensland

14 The Motor Report, Victoria's New Hoon Laws in Effect from Tomorrow, 30 June 2011,

<http://www.themotorreport.com.au/52033/victorias-new-hoon-laws-in-effect-from-tomorrow> (accessed 28 February 2012).

15 Northern Territory Transport Group, New Anti-hooning Legislation, Department of Lands and Planning's Transport Safety Branch, Darwin,

<http://www.transport.nt.gov.au/safety/road/priorities/antihooning/index.shtml> (accessed 20 February 2012).

16 John M. Williams, 'Law and Order, No End in Sight', Trends and Issues 2006 Update, The State of South Australia, 2006, Australian Institute of Social Research, University of Adelaide and Don Dunstan Foundation.

17720 ABC Perth, 'Hoon Laws to Remain Intact', News, 28 January 2010 15:36:00,

<http://www.abc.net.au/news/stories/2010/01/08/2788412.htm?site=perth> (accessed 28 February 2012).

18 Wayne Jarred, 'Police Powers and Responsibilities Act Amendment Bill 2002: Confronting Bad and Nuisance Road Behaviour', Research Brief No. 2002/18, Queensland Parliamentary Library, Brisbane, 2002.

19 Staysafe 35 , p. 15 , emphasis added.

20 Fuller, pp. 125-36.

${ }^{21}$ Kerry A. Armstrong and Dale A. Steinhardt, “Understanding Street Racing and "Hoon” Culture: An Exploratory Investigation of Perceptions and Experiences', Journal of the Australasian College of Road Safety, vol. 17, no.1, 2005, pp. 38-44.

22 Queensland Transport, Road Traffic Crashes in Queensland 2003: A Report on the Road Toll, Queensland Transport, 2005 <http://www.tmr.qld.gov.au/ /media/ea49272b-48c2-4151-9c98b518135220a2/road_traffic_crash_report_2003_v2.pdf> (accessed 20 February 2012). ${ }^{23}$ Jarred explains that imprisonment was introduced as a sanction for driving negligently resulting in death or causing grievous bodily harm; driving behaviour determined to be furious, reckless or at a speed or in a manner that is dangerous to the public; or driving that is intentionally or deliberately menacing to another person (manifest in a threat to personal injury or to damage property). 
24 Jarred.

25 Ibid., p. 1.

26 Ibid., p. 2.

27 Ibid., pp. 2-3, emphasis added.

${ }^{28}$ Media release, South Australian Government,

<http://www.ministers.sa.gov.au/news.php?id=1227Bottom of Form>, 8 February 2007 (accessed 18 November 2008).

${ }^{29}$ Brandon LaBelle, Acoustic Territories, Sound Culture and Everyday Life, Continuum International Publishing Group, New York, 2010, p. xxii.

30 Ibid., pp. 47-8.

31 Ibid., p. 53.

32 Pauline McGuirk and Robyn Dowling, 'Neoliberal Privatisation? Remapping the Public and the Private in Sydney's Masterplanned Residential Estates', Political Geography, vol. 28, 2009, p. 175.

33 Christopher Mele, 'Casinos, Prisons, Incinerators, and other Fragments of Neoliberal Urban Development', Social Science History, vol. 35, no. 3, 2011, pp. 424, 446; Julian Brash, 'The Ghost in the Machine: The Neoliberal Urban Visions of Michael Bloomberg', Journal of Cultural Geography, vol. 29, no. 2, 2012, p. 149.

34 Edward J. Blakely and Mary Gail Snyder, Fortress America: Gated Communities in the United States, Brookings Institution Press, Washington DC, 1997, p. 8.

35 LaBelle, p. 55.

36 Ibid., p. 58.

37 Tasmania Police, 'Anti-hooning_Law Empowers Police to Confiscate Cars', 2008 $<$ www.police.tas.gov.au/road_safety/anti-hooning_law> (accessed 12 November 2008).

38 Government of South Australia, 'Police Nab 3000th Hoon Driver, 23 July 2008', Action Now for the Future, <www.ministers, sa.gov.au/news.php?id=3471> (accessed 18 November 2009).

${ }^{39}$ Minister for Police and Emergency Services, Victoria, 'Time's Almost up for Hoon Drivers: New Laws 1 July', Media Release, 27 June 2006.

40 Sharpe.

${ }^{41}$ LaBelle, p. 150.

42 George Prochnick, In Pursuit of Silence: Listening for Meaning in a World of Noise, Doubleday, New York, 2010, p. 220.

43 Ibid., p. 218.

44 Ibid., p. 222. There are similar projects in Holland, Japan and Korea,

<http://kaleidophonic.wordpress.com/2012/09/04/musical-rumble-strips/>;

<http://gigdoggy.wordpress.com/2008/09/23/groove-encrusted-asphalt-to-bring-musical-roads-atthe-top-of-the-charts/>. 
45 Tom O’Dell, 'Raggare and the Panic of Mobility: Modernity and Hybridity in Sweden' in Car Cultures, ed. Daniel Miller, Berg, Oxford, pp. 122-5.

46 Labelle, Prochnick.

47 Leal et al.

${ }^{48}$ Armstrong and Steinhardt.

49 The Motor Report.

50 Gerry McCarthy, Transport Legislation (Hoon Behaviour) Amendment Bill, Northern Territory Second Reading Speeches, 2009 Austlii,

<http://www.austlii.edu.au/au/legis/nt/bill_srs/tlbab2009495/srs.html> (accessed 28 February 2012).

51 Leal et al.

${ }^{52}$ Andrew Leigh, 'Youth and Street Racing', Current Issues in Criminal Justice, vol. 3, 1996, pp. 388-93.

${ }^{53}$ Armstrong and Steinhardt. See also Leigh, and Prochnick, 'Soundkill' in Prochnick, In Pursuit of Silence, pp. 123-54, regarding the characteristics of car enthusiasts.

${ }^{54}$ Armstrong and Steinhardt p. 40.

55 Fredric Miyara, 'Acoustic Violence: A New Name for an Old Social Pain', Hearing Rehabilitation Quarterly, vol 24, no. 1, 1999, p. 18.

56 LaBelle, p. 80.

${ }^{57}$ Michel Foucault, Discipline and Punish: The Birth of the Prison, Vintage Books, New York, 1979. 